\title{
Performing Evolution: Role-Play Simulations
}

\author{
Rebecca M. Price
}

Published online: 29 December 2010

(C) Springer Science+Business Media, LLC 2010

\begin{abstract}
By simulating evolution through performance, students become physically, as well as mentally, engaged in thinking about evolutionary concepts. This instructional strategy redirects tension around the subject toward metacognitive reflection. Non-verbal performances like those presented here also avoid the pitfalls of relying on difficult-to-use language. This paper describes a teachable unit including the learning goals and outcomes as well as rubrics to aid assessment. Through two performance-based activities, the unit introduces the fundamental evolutionary concepts that evolution lacks forethought and that natural selection is a sorting process. By reflecting on the performances, students learn other sophisticated evolutionary concepts like hitchhiking, the effects of environmental change, and the extinction of traits. They also become aware of the scientific process, articulating hypotheses about the outcome of the simulations, collecting data, and revising their hypotheses. Discussions and homework about the performances reveal how learning progresses, and detailed rubrics help both instructors and students assess conceptual learning. This unit concludes with the opportunity for students to transfer what they have learned to new concepts: they design new performances to simulate other mechanisms of evolution, such as genetic drift, mutation, and migration.
\end{abstract}

Keywords Interdisciplinarity $\cdot$ Performing arts $\cdot$ Kinesthetic learning $\cdot$ Role-play $\cdot$ Natural selection $\cdot$ Simulation .

Scientific teaching

R. M. Price $(\bowtie)$

Interdisciplinary Arts and Sciences Program,

University of Washington,

Box 358511, 18115 Campus Way NE,

Bothell, WA 98011-8246, USA

e-mail: becca.price@uwb.edu

\section{Introduction}

Even students who are curious to learn about evolution are often intimidated by it. When the subject is broached in the classroom, many students are immediately on the defensive, either as proponents of evolution or as creationists. Most introductory biology freshmen cannot define evolution even when they accept it as a scientific explanation (Jakobi 2010). Some students are afraid to learn about evolutionthe misconception that evolution is entirely random can intimidate people so much that it keeps them from exploring what evolution is actually about (Mead and Scott 2010b; Miller 2002). This discomfort is exacerbated by conflating the lack of direction in evolution with a spiritual lack of purpose in life (Mead and Scott 2010a).

The single most important achievement for an instructor is to engage all students, regardless of religious background and alternative conceptions, with the fundamental logic supporting evolution (Scott 2010). Engagement helps students move beyond their apprehension, changing the timbre of the conversation from defense to learning. Dramatizing conceptual challenges - turning them into performances - helps students learn by redirecting emotion into physical movements (Harrison-Pepper 1999), so students can focus their thinking on the science.

Performance-based activity also called role-play or simulation-role-play (Aubusson and Fogwill 2006) is a form of kinesthetic learning that excels at encouraging reflection and participation (Harrison-Pepper 1999). Students who choreograph gestures with new material are better at remembering what they have learned (Cook et al. 2008). They develop metacognitive skills by analyzing the efficacy of the performance analogy (Harrison and Treagust 2006). They also learn to communicate across disciplines and become more explicitly aware of the creative nature of 
scientific discovery (Aubusson and Fogwill 2006; Nikitina 2003). Removing verbal language reaches across linguistic boundaries; students rely more on kinesthetic learning when taking a class in a language different from their native one (Reid 1987). The jargon that can become a barrier to engaging students in evolution in particular (Mead and Scott 2010a) is also removed, as are misleading anthropomorphic metaphors like "wanting" to change (Sinatra et al. 2008). By participating in a performance, the experience is - at least in this fleeting momentpersonally relevant. Teaching that involves metacognition and personal relevance challenges intuitive conceptions in a way that is necessary to drive conceptual change towards a scientific framework for evolutionary thinking (Sinatra et al. 2008).

Nonetheless, performance-based activities have been under-utilized in higher education (Harrison-Pepper 1999; Nikitina 2003). Role-play has been used in K-12 science education to great effect, for example to dramatize how molecules ionize in different solutions (Aubusson and Fogwill 2006), but few examples exist for college biology, with notable exceptions for cell division and the central dogma (Kreiser and Hairston 2007; Weiss 1971).

This paper describes a teachable unit (Handelsman et al. 2007) with learning goals and outcomes, two performancebased activities (Evolution lacks forethought and Performing natural selection) and assessment. The activities explore heritability, variation, fitness, and natural selection to introduce fundamental concepts that form the basis of evolutionary thinking. Understanding builds from natural selection to other mechanisms of evolutionary change (Wilson 2005). I developed the unit for students in their first quarter of college at an interdisciplinary program. Although a few of the students in this class do pursue biology majors, the vast majority do not.

\section{Concepts Addressed}

This teachable unit addresses challenging concepts of evolutionary thinking in general and of natural selection in particular (Table 1; concepts and misconceptions from Gregory 2009). The primary concepts addressed are the three tenets of natural selection: heritable variation exists in populations, more offspring are born than can survive and the offspring that do survive are the ones most suited to their environment. In these activities, a thorough understanding of survival of the fittest develops by working through other concepts, including the fact that natural selection acts in the moment instead of planning ahead and the fact that the environment dictates which variants will survive. Students learn the difference between sorting and creative processes, recognizing that natural selection is a sorting process that leads to a change in the proportion of variants over time. These basics lay the foundation for learning that not all evolution is natural selection (Wilson 2005), and Performing natural selection explicitly addresses the fact that nonadaptive traits can hitchhike along with adaptive traits.

Table 1 lists so many concepts that instructors who use this unit will probably want to prioritize which ones to

Table 1 Concepts addressed (compiled, with the exception of hitchhiking, from Gregory 2009)

\begin{tabular}{ll}
\hline Concept & Common misconception
\end{tabular}

1 Heritable variation, overproduction of offspring, and survival of the fittest are all required for natural selection to occur.

2 Natural selection works in the moment, lacking forethought.

3 In evolution by natural selection, the environment dictates which variants will survive.

3a Fitness to the environment leads to heritable change.

$3 \mathrm{~b}$ Fitness enhances survival.

$3 \mathrm{c}$ The results of natural selection are predictable in a constant environment.

4 Natural selection is a process that sorts different variants.

4a Variation already exists in the population.

$4 \mathrm{~b}$ Natural selection results in a decrease of variation over time; some traits go extinct.

$4 \mathrm{c}$ The proportion of variants changes over time.

4d Maladaptive traits can be inherited, too.

5 Not all evolution is natural selection.

5a Nonadaptive traits can hitchhike along with adaptive traits.
Any single tenet is sufficient for natural selection to occur.

Organisms plan ahead for the long-term survival of the species.

The environment dictates new traits that will be acquired.

Individuals "want" or "need" to change.

The fittest individuals are the physically strongest.

Evolution is random and therefore unpredictable.

Natural selection is an agent that chooses superior individuals.

New variants evolve in response to need.

Natural selection is a creative process.

All of the individuals in a species change simultaneously.

Maladaptive traits disappear immediately because they are not used.

Natural selection and evolution are synonymous.

All traits result from natural selection. 
address in their classrooms. One way to decide what to emphasize is to administer the Concept Inventory of Natural Selection (Anderson et al. 2002) at the beginning of the unit to determine where students require the most help. The unit is flexible enough to be retooled easily to address the concepts that each instructor emphasizes.

\section{Learning Goals and Outcomes}

Handelsman et al. (2007) define learning goals as the content that students will know and the skills that students will have after successfully completing an exercise; outcomes explain the way student performance indicates mastery. The learning goals of this exercise focus on the conceptual understanding of natural selection, and the outcomes expect that a strong understanding of natural selection can be applied to develop a strong understanding of other mechanisms of evolutionary change (Table 2). Each learning goal and outcome corresponds to different concepts from Table 1.

\section{Activities}

The activities are designed to motivate students to participate fully in class, but also to work outside of the class where most learning occurs (Handelsman et al. 2007). I have developed rubrics to aid in the formative assessment of Evolution lacks forethought and Performing natural selection. These rubrics explain how each activity addresses the concepts in Table 1.

\section{Warm-Up}

Because it is unusual for science students to learn through movement, it is essential to establish early in the term the precedent that students will employ this learning style. A 15-minute ice breaker (from Boal 2002) introduces this mode of learning on the first day of class while students are fresh and enthusiastic. My classes are capped at 45 students - with a larger class, I would divide the group into two sections to do this warm-up:

Step 1. The class arranges itself in a circle.

Step 2. I briefly explain and demonstrate that students can move by changing their facial expression, moving their head or a limb, or by shifting their weight.

Step 3. Each student makes a movement while stating his or her name. For example, I say "Becca" and roll my head around.

Step 4. Everyone else simultaneously copies the movement while repeating the name. Continuing with the same example, the whole class says "Becca" and mimics my head roll.

Step 5. Proceed around the circle, repeating steps 3 and 4, until each student has taken a turn. It is best if students make a movement that no one else has performed.

Table 2 Student learning goals and outcomes

\begin{tabular}{|c|c|c|c|}
\hline & Goals & Outcomes & Concepts \\
\hline I & $\begin{array}{l}\text { List the requirements for different mechanisms } \\
\text { of evolution, explaining how stages in the differently } \\
\text { performed simulations illustrate each. }\end{array}$ & $\begin{array}{l}\text { Construct diagrams similar to Fig. } 2 \text { that predict the } \\
\text { outcomes of simulations, but for situations in which } \\
\text { not all of the requirements have been met. Do this for } \\
\text { natural selection, mutation, migration, and genetic drift. }\end{array}$ & 1,5 \\
\hline II & $\begin{array}{l}\text { Resolve the paradox that natural selection responds } \\
\text { to the moment, but that it is also appropriate for } \\
\text { predicting certain results. }\end{array}$ & $\begin{array}{l}\text { Predict the results of natural selection when appropriate } \\
\text { (e.g., antibiotic resistance), recognizing that the } \\
\text { environmental factors that define selective pressure } \\
\text { remain constant. } \\
\text { Analyze case studies to determine whether natural } \\
\text { selection, mutation, migration, or genetic drift is } \\
\text { occurring. }\end{array}$ & $2,3,3 \mathrm{a}, 3 \mathrm{~b}, 3 \mathrm{c}$ \\
\hline III & $\begin{array}{l}\text { Explain why natural selection is a sorting process } \\
\text { and why mutation, migration, and genetic drift } \\
\text { are not. }\end{array}$ & $\begin{array}{l}\text { Choreograph a performance that illustrates the difference } \\
\text { between sorting, creative, and random processes. } \\
\text { Categorize different mechanisms into sorting, creative, or } \\
\text { random processes. }\end{array}$ & $4,4 \mathrm{a}, 4 \mathrm{~b}, 4 \mathrm{c}, 4 \mathrm{~d}, 5$ \\
\hline IV & $\begin{array}{l}\text { Recognize natural selection is only one of the several } \\
\text { mechanisms of evolutionary change. }\end{array}$ & $\begin{array}{l}\text { Find hitchhiking traits in simulations and case studies. } \\
\text { Choreograph performance-based simulations that illustrate } \\
\text { and analyze other mechanisms of evolutionary change, } \\
\text { including mutation, genetic drift, and migration working } \\
\text { independently of or along with natural selection. }\end{array}$ & $5,5 \mathrm{a}$ \\
\hline
\end{tabular}

Concepts are keyed to Table 1 
Some students may unintentionally make a movement while they are thinking about what to do: a flick of the hair, for example, or shifting weight from foot to foot. I embrace these gestures to demonstrate that simple poses are entirely adequate, that movements like these are a part of everyday communication. This encouragement builds rapport by illustrating that movement is natural and easy, not daring and foreign. Some one-on-one encouragement helps reticent students, and simple accommodations can be made for students with limited mobility. For example, if a student jumps into the circle while saying her name, a student in a wheelchair can modify the movement by moving his chair into the circle.

This warm-up activity serves two other purposes. It is an excellent way for both the instructor and the students to learn names: gestures are associated with memory (Cook et al. 2008) - think of someone gesticulating while reaching for a word - and students and I often learn each others' names by remembering their movements. This exercise also introduces a movement vocabulary. Students become aware of the number of different poses that they can assume, a crucial step for completing the other activities.

\section{Evolution Lacks Forethought}

This performance takes about 15 minutes, although the discussion about the topics introduced can last much longer depending on how well the students understand the material and what the instructor aims to achieve. I set the stage by saying that we are experiencing a rapidly and unpredictably changing environment and that individuals are constrained by their past. The activity then proceeds as follows (Fig. 1):

Step 1. Students line up.

Step 2. The first student strikes a pose. This can be any random pose that he or she chooses.

Step 3. Working independently, each student predicts what the last pose will be, jotting down a note or a sketch.

Step 4. The second student mimics the first pose, but can change one and only one aspect of that pose.

Step 5. The third student mimics the second pose, changing one and only one aspect of it. Continue through the line.

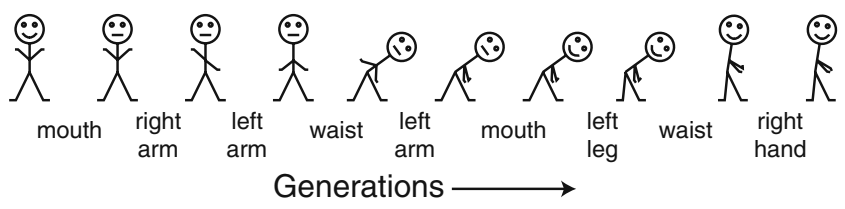

Fig. 1 Evolution lacks forethought. Ten students line up. Each adopts the previous student's pose, but changes one aspect of it. The aspect that changes is indicated at the bottom of the diagram. None of the students can deduce how the simulation will end
Step 6. Students describe - with words or sketches - how shape changed during the simulation, comparing the result to their predictions.

Step 7. Students work in pairs to discuss the questions in Table 3.

Step 8. Debrief as a whole class.

Forming a prediction (step 3) is crucial to the success of this activity, so students should write down their predictions and save them for later discussion. Predictions improve learning by actively engaging students in a demonstration (Crouch et al. 2004). More than that, however, is the fact that these predictions help students distinguish between evolutionary constraint and evolutionary unpredictability. By the end of the activity, students realize that they can fairly accurately predict the pose from one generation to another because only one aspect of the pose can change. In Fig. 1, for example, the second pose is almost entirely the same as the first pose; only the shape of the mouth differs. But students also realize the complementary point that they cannot predict the way several changes accrue over many generations. In Fig. 1, it is impossible to predict with certainty that the last person will be leaning slightly to the right with both arms on the right side of the body and hands pointing in different directions. The fact that the series involved two incidences of homoplasy (losing and regaining a smile, losing and regaining an upright posture) was also unpredictable. The questions in Table 3 guide students toward realizing that the unpredictability in natural selection is due to a rapidly and unpredictably changing environment that favors different poses through several generations. I push this concept even further by encouraging students to think about nonadaptive evolution. I ask them to imagine a simulation with the same outcome in which natural selection was not occurring, giving us an opportunity to discuss neutral evolution.

As with any analogy, this performance has its shortcomings in how accurately it portrays evolution. These shortcomings provide another opportunity to learn through analyzing the accuracy of the analogy (Harrison and Treagust 2006). Performing natural selection actively engages students in the idea that proportions of a trait change in the population, but Evolution lacks forethought assumes that each individual represents an entire generation. Similarly, Performing natural selection represents heritable variation with more sophistication and more clearly illustrates selection as a sorting process rather than a mechanism by which an agent chooses a trait. The role of mutation in Evolution lacks forethought is unclear. One interpretation is that each new pose is a mutation that evolved de novo. I prefer a more abstract macroevolutionary interpretation, that the variation for all the poses is maintained in the genome, but not expressed because the genes are turned off. The mutations 
Table 3 Rubric for evaluating questions about Evolution lacks forethought

\begin{tabular}{|c|c|c|c|}
\hline Question & $\mathrm{C}$ & \multicolumn{2}{|c|}{ Quality of student work. Student... } \\
\hline \multirow[t]{4}{*}{$\begin{array}{l}\text { Were you able to predict the outcome of this simulation? } \\
\text { Why? }\end{array}$} & \multirow[t]{4}{*}{2} & $\mathrm{~S}$ & $\begin{array}{l}\text { explains "no" because each individual responds with a pose in the } \\
\text { moment, considering only the immediately preceding pose and } \\
\text { without reference to future poses. }\end{array}$ \\
\hline & & G & says "no," but the explanation is incomplete. \\
\hline & & NI & $\begin{array}{l}\text { says "yes" or "no"; explanation was made with fair effort, but } \\
\text { reveals misconceptions, such as that evolution is entirely } \\
\text { random. }\end{array}$ \\
\hline & & $\mathrm{U}$ & says "yes" or "no" without offering any explanation. \\
\hline \multirow[t]{4}{*}{ How is this simulation like evolution? } & \multirow[t]{4}{*}{2} & $\mathrm{~S}$ & $\begin{array}{l}\text { explains the phrase "evolution lacks forethought," noting that the } \\
\text { rapidly and unpredictably changing environment results in fast } \\
\text { changes in selective pressures; observes that individuals are } \\
\text { constrained by their ancestry, and recognizes that mutations } \\
\text { accrue at a constant rate. }\end{array}$ \\
\hline & & G & $\begin{array}{l}\text { includes inaccuracies while explaining what "evolution lacks } \\
\text { forethought" means, for example stating that individuals mutate } \\
\text { in response to environmental change. }\end{array}$ \\
\hline & & NI & $\begin{array}{l}\text { parrots the phrase "evolution lacks forethought" without indicating } \\
\text { an understanding of what it means. }\end{array}$ \\
\hline & & $\mathrm{U}$ & is unable to find similarities. \\
\hline \multirow[t]{4}{*}{ How does this simulation differ from evolution? } & \multirow[t]{4}{*}{$4 \mathrm{a}, 4 \mathrm{~b}, 4 \mathrm{c}$} & $\mathrm{S}$ & $\begin{array}{l}\text { explains that individuals choose their poses, that this simulation } \\
\text { does not illustrate a sorting process, and that each person } \\
\text { represents an entire generation. }\end{array}$ \\
\hline & & G & addresses some, but not all of the similarities listed above. \\
\hline & & NI & $\begin{array}{l}\text { makes a fair attempt to answer the question, but fails to construct a } \\
\text { logical argument. }\end{array}$ \\
\hline & & $\mathrm{U}$ & is unable to find differences. \\
\hline \multirow[t]{4}{*}{$\begin{array}{l}\text { Why do the rules of the simulation specify that the } \\
\text { environment was changing rapidly? }\end{array}$} & \multirow[t]{4}{*}{$3,3 a, 3 c$} & $\mathrm{~S}$ & $\begin{array}{l}\text { recognizes that the environment is a constantly changing filter that } \\
\text { selects different poses; explains that the act of assuming a pose is } \\
\text { an analogy for the environment dictating which pose is selected. }\end{array}$ \\
\hline & & G & $\begin{array}{l}\text { recognizes that the environment is a constantly changing filter that } \\
\text { selects different poses, but does not recognize that assuming a } \\
\text { pose is an analogy for selection. }\end{array}$ \\
\hline & & NI & $\begin{array}{l}\text { associates environmental change with natural selection without } \\
\text { explaining that the environment is the filter that dictates survival. }\end{array}$ \\
\hline & & $\mathrm{U}$ & fails to associate environmental change with natural selection. \\
\hline \multirow{4}{*}{$\begin{array}{l}\text { How would the results of the simulation change if the } \\
\text { environment remained stable and if natural selection } \\
\text { did not occur? Why? }\end{array}$} & \multirow[t]{4}{*}{5} & $\mathrm{~S}$ & $\begin{array}{l}\text { recognizes that rapid but neutral evolution through genetic drift } \\
\text { can result in the same pattern observed. }\end{array}$ \\
\hline & & $\mathrm{G}$ & $\begin{array}{l}\text { recognizes rapid but neutral evolution through genetic drift, but } \\
\text { does not address how the results of the simulation could change. }\end{array}$ \\
\hline & & NI & $\begin{array}{l}\text { recognizes that natural selection is not occurring, but does not } \\
\text { explain accurately how these changes can occur; for example, } \\
\text { argues that mutation causes all the change without reference to } \\
\text { selection or drift. }\end{array}$ \\
\hline & & U & guesses or does not attempt to explain answer. \\
\hline
\end{tabular}

$C$ concepts (keyed to Table 1), $S$ sophisticated, $G$ good, NI needs improvement, $U$ unacceptable

that occur in each generation are mutations in the regulatory control mechanisms, activating some aspects of a pose and deactivating others.

To encourage students to continuing grappling with the topics raised in this activity, I recommend that instructors ask students to write out answers to the questions in Table 3 for homework. Instructors can grade the answers according to the rubric (Table 3) or ask students to grade each others' papers in class the next meeting.

\section{Performing Natural Selection}

This performance takes approximately half an hour, and discussion continues after that. For simplicity, the description 
below assumes a class of 24 students, although I typically use it in a class size of 45 and I have used it in classes as large as 85. In this simulation, each round represents a generation.

Step 1. Two students act as predators, and at least two more act as recorders. The predators and recorders count the number of prey with the trait under selection, and a ratio of four predators and recorders to 20 prey means that each predator or recorder only has five people to assess when counting the number of individuals with the trait under selection, so the performance can proceed quickly.

Step 2. The rest of the students are prey, and they distribute themselves throughout the room and strike a unique pose (Fig. 2).
Step 3. The predators and recorders define a maladaptive trait, some aspect of a pose that makes prey attractive to predators, for example "hands above the waist." The predators and recorders keep the criterion a secret. The prey's ignorance ensures that the performance represents a sorting process, and therefore, the exercise must begin again if the prey knows the predators' criterion.

Step 4. The predators and the recorders count the number of prey that express the maladaptive trait, and the recorders tabulate the data for the whole class to see. The individuals acting as prey map the class (for a large class, they can map the subsample of students closest to them), noting the poses for each prey individual. The maps approximate the cells in Fig. 2.

\section{Round 1}

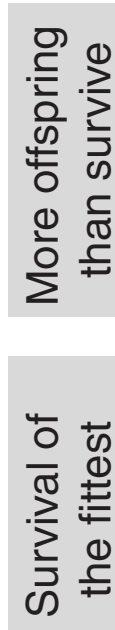

Round 2

\section{Round 3}
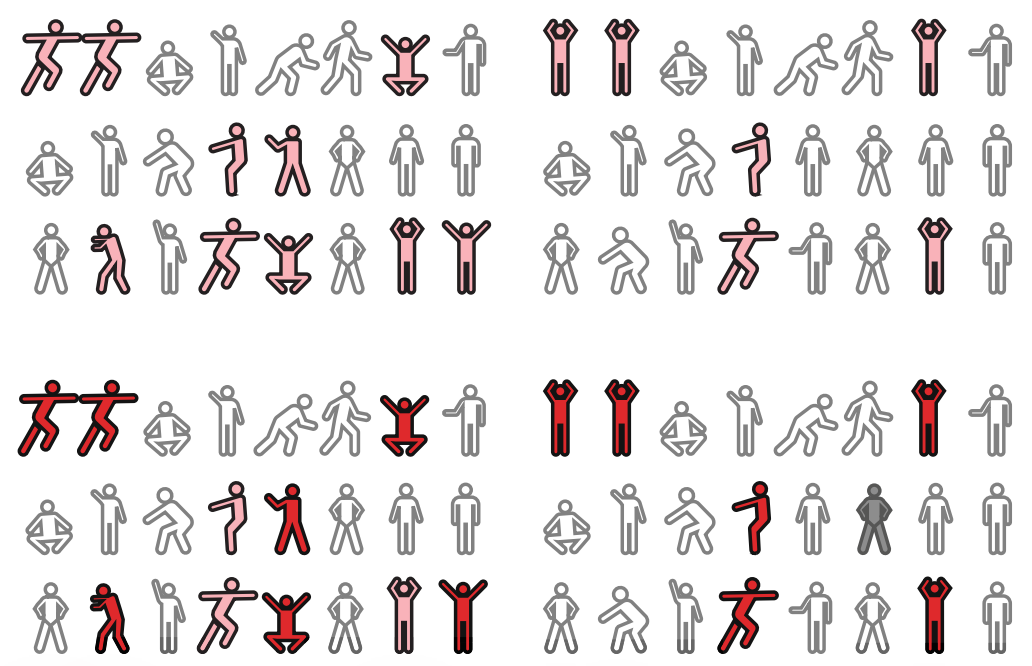

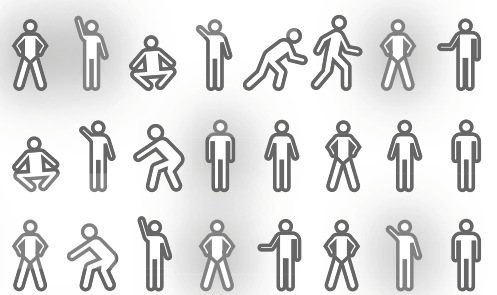

change in frequency
Fig. 2 Performing natural selection. The first round begins with 24 unique poses. The first row distinguishes between individuals with and without the trait "hands above the waist." The prey that are captured are highlighted in the second row. Reproduction occurs between the second and third rows. Survivors are cloned, some more than once so that population size returns to 24 . The poses that replace those that went extinct are emphasized with a gray cloud to indicate that the frequency of "hands above the waist" has changed. Some of these replacement poses have the maladaptive trait at the end of rounds 1 and 2 because the maladaptive trait is still present among survivors. By the end of round 3, however, no survivor has the trait. The frequency of the maladaptive trait moves from 0.58 at the beginning of round 1 to 0.0 at the end of round 3, and the number of poses drops from 24 at the beginning of the simulation to ten at the end 
Step 5. The predators, moving from opposite sides of the room, have ten seconds to hunt, an interval that is short enough that some of the individuals with the maladaptive trait will remain in the population. Predators hunt by walking toward prey and touching them on the shoulder. Every time a predator touches a prey, that prey dies.

Step 6. Reproduction occurs when survivors clone their ancestors' poses; in practice, this means that the survivors can move to a different spot in the room, but they need to keep the same pose. The students who represented dead prey re-enter the population as babies, copying the pose of any survivor. The predators and recorders now re-count the number of individuals in the population with the maladaptive trait.

Step 7. The students representing the prey record their hypothesis about which trait they think is under selection.

Step 8. Round 2 occurs, repeating Steps 4, 5, 6, and 7.

Step 9. Round 3 follows exactly like Round 2, etc. Three rounds are usually sufficient to demonstrate selection, and the maladaptive trait may even have gone extinct as in Fig. 2. Conclude with the tabulations in step 4.

Step 10. Students work in pairs to discuss the questions in Table 4.

Step 11. Debrief as a whole class.

The steps in the performance mimic the tenets of natural selection (Fig. 2). When the prey individuals are waiting to be hunted (step 4), it is obvious that more of them are alive than will survive. The individuals that are hunted have a maladaptive trait, indicating that they are less fit to survive (step 5). Heritable variation is illustrated by step 6 . The survivors clone themselves, and so of course the survivors represent existing variation. The way heritable variation is emphasized occurs when the actors that had represented dead individuals re-enter the population as babies, bringing the population back to its original size. These new individuals must copy the pose of any survivors. They cannot invent new variation. This subtlety is critical for illustrating to students that natural selection will, over the long term, lead to the extinction of maladaptive traits.

The performance introduces the concept of hitchhiking. The students who act as prey continually hypothesize about which trait is under selection; some of their hypotheses may appear to be correct, even when they are not, because all of the individuals who were selected may share additional traits other than the one that was under selection. In Fig. 2, for example, the "hands above the waist" is selected against, but all of the survivors have "both feet on the ground" in addition to having "a hand at or below the waist."
After the performance, students work in pairs to answer the questions in Table 4. These questions ask students to draw diagrams that show how evolution proceeds under different conditions. For visual learners, these maps are an effective tool for contemplating and describing each step (Felder and Brent 2005). Because I want my students to supplement their visual understanding with the ability to describe evolution verbally, I also ask students to answer the questions orally, for example by presenting their diagrams to the whole class for discussion, or in writing answers to the questions as homework.

By answering the questions, students apply the tenets of natural selection and explore the interaction between selection and the environment. They study the data generated by the performance, documenting hitchhiking of some traits and the extinction of others by looking at how the proportions of different traits change in the population through time. By the end of the discussion, they can distinguish between sorting, creative, and random processes in evolution.

As with Evolution lacks forethought, students greatly benefit from discussing the limits of this analogy of natural selection. This discussion can occur at the end of this teachable unit, or the instructor may choose to return to this analogy after students work with natural selection in other contexts. Students will likely observe that this simulation does not address how variation is introduced into the population: mutation and recombination are not addressed. Macroevolutionary concepts like heterochrony and speciation are also absent. For some students, though, this exercise triggers new questions about macroevolution, and they begin anticipating future teachable units, asking how changes accrue over time. The simulation also de-emphasizes the role of differential reproduction because everyone reproduces at the same rate and at the same time.

\section{Assessment}

The discussion, drawings, and written exercises that immediately follow the performances provide opportunities for formative assessment (assessment during the teachable unit; Handelsman et al. 2007), and the summative assessments (assessment at the end of the unit; Handelsman et al. 2007) that I describe in this section ask students to translate what they have learned into new contexts. This process of translation helps change prior conceptions, allowing students to construct a new and more accurate conceptual framework (Bransford et al. 2000) and leading to the outcomes specified in Table 2.

\section{Scientific Inquiry}

Learning is enhanced when students are aware of the steps they have taken to construct their knowledge (Bransford et 
Table 4 Rubric for evaluating questions about Performing natural selection

Question

How does this simulation illustrate heritable variation in a population?

1

C

S

How do you know more offspring are born than can survive?

Predict how the population would evolve if one of the tenets of natural selection did not happen. Illustrate your predictions with diagrams similar to Fig. 2. (I: overabundance of offspring; II: survival of the fittest; III: heritable variation)

Why is natural selection a sorting process?

This simulation models selective pressure against certain traits - having a certain trait makes an individual more attractive to a predator. How would you model selective pressure towards a certain trait-having a trait that makes you less attractive to or immune to an attack by a predator?

$3 \mathrm{c}, 4,4 \mathrm{c}$
Quality of student work. Student...

$\mathrm{S}$ recognizes that each round represents a new generation, and the survivors reproduce by making copies of themselves; only the surviving traits persist in the population because the variation is heritable. The other traits have gone extinct.

limits discussion to the fact that only the survivors can reproduce and that offspring copy a parent's pose.

recognizes that only the survivors can reproduce, but does not understand the importance of offspring copying the poses of their parents.

does not distinguish between heritable and acquired change.

recognizes that the predators reduce population size and that reproduction returns population size to carrying capacity.

knows that predators decrease population size and reproduction increases it, but does not explain why population size remains stable.

knows that predators decrease the population size of prey, but does not acknowledge that reproduction increases it.

fails to recognize that predators decrease population size prior to reproduction.

modifies Fig. 2 accurately and clearly to illustrate that only I and II does not change the genetic frequency of traits; only I and III leads to random survival instead of a sorting process; only II and III cannot cause change because population size will not decrease.

addresses each of the three scenarios, but the illustrations reveal confusion and do not provide clear explanations.

does not entertain all possible combinations. For example, the student looks only at I and II, but does not consider I and III or II and III.

does not form a coherent prediction or does not explain the reasoning underlying the prediction.

explicitly states that natural selection is a passive process, and explains that an environmental filter discriminates between individuals with and without a trait.

explains that natural selection is a filter that discriminates between individuals with and without a trait.

struggles to explain what a sorting process is.

assumes agent of change; does not recognize that a sorting process is passive.

recognizes that positive and negative selection are relative terms - in this model, all the traits that are not selected against are actually selected for; the same simulation works for both points of view.

recognizes that positive and negative selection are relative terms; struggles to illustrate this point with a simulation.

recites the differences between positive and negative selection, but does not see them as two sides of the same coin and cannot apply those definitions to answer the question. does not distinguish between positive and negative selection. explains that natural selection changes the frequency of a trait and can through time, provided constant selective pressure across generations, lead to the extinction of a maladaptive trait.

G explains that natural selection changes the frequency of a trait across multiple generations, but does not discuss the extinction of a maladaptive trait.

NI struggles with the concept of frequency or does not explain that frequency changes across generations.

$\mathrm{U}$ fails to understand negative selection and relies on the common misconception that, when change occurs, it occurs to all of the individuals in the population (Gregory 2009). 
Table 4 (continued)

Question $\quad$ C

Quality of student work. Student...

What would happen if the predators' prey preference changed? Why? $3,3 \mathrm{a}, 3 \mathrm{~b}, 3 \mathrm{c}$
$4,4 \mathrm{c}$
S

$\mathrm{U}$

What would happen if you added a second species of predator with a different prey preference?

Why do some individuals with maladaptive traits re-enter the population? At what point does this stop?
$2,3,3 \mathrm{a}, 3 \mathrm{~b}, 3 \mathrm{c}$ $4,4 \mathrm{a}$
$\mathrm{S}$ recognizes that the shift in prey preference represents a shift in the environment and that the trait that had been selected against is now being selected for; similarly, a trait that had been adaptive is now maladaptive.

G recognizes a new selective pressure, and that the trait that had been selected against is now being selected for; does not generalize that changing prey preference is a form of environmental change.

recognizes a new selective pressure, but cannot predict the outcome of the change.

argues that it is impossible to predict.

recognizes that the second predator is a type of environmental change that causes a trait that had been adaptive to be maladaptive; natural selection would happen more quickly in this simulation, because more prey would die during each round.

recognizes that two selective pressures are now present and that a trait that had been adaptive is now maladaptive, but does not recognize the change in rate of natural selection.

recognizes that a second trait is maladaptive, but cannot predict how the prey population will respond.

$\mathrm{U}$ argues that it is impossible to predict.

recognizes that all of the survivors reproduce, even those who have the maladaptive trait; may point out a limitation in the exercise that differential reproduction is not considered.

$\mathrm{G}$ recognizes that all of the survivors reproduce, even those who have the maladaptive trait.

NI observes that the predators did not consume all of the attractive prey, but does not acknowledge that some of these survivors may reproduce.

$\mathrm{U} \quad$ invokes another mechanism of evolution, arguing that maladaptive traits cannot exist in the population if natural selection is occurring; does not recognize that natural selection changes the frequency of a trait in a population.

If the environment remains stable, and natural selection is occurring, what happens to the number of variants over time? Why? recognizes that natural selection decreases the amount of variation in a population because individuals with the maladaptive trait eventually go extinct.

$\mathrm{G}$ recognizes that natural selection decreases the amount of variation in a population because individuals with the maladaptive trait die, but does not acknowledge that these traits are completely extinct.

NI states that natural selection decreases the amount of variation but does not explain why.

$\mathrm{U} \quad$ states that the number of variants stays the same or increases; fails to justify answer.

recognizes that reasonable hypotheses about which trait was under selection had to be rejected; revises hypothesis during the performance by observing the poses that were selected by predators; draws from rejected hypotheses to identify traits that hitchhiked.

revised hypothesis during the performance and identifies traits that hitchhiked; does not explicitly analyze the data from the performance.

NI recites a definition of hitchhiking, but does not draw on the performance to explain the definition.

$\mathrm{U}$ fails to thoughtfully contemplate on the data and does not demonstrate an understanding of hitchhiking.

Abbreviations as in Table 3 
Table 5 Rubric for a performance simulation that students design

\begin{tabular}{|c|c|c|c|c|}
\hline \multirow{2}{*}{$\begin{array}{l}\text { Criterion } \\
\text { Identifies and explains the utility of the } \\
\text { parameters in the simulation }\end{array}$} & \multirow{2}{*}{$\mathrm{C}$} & \multirow{2}{*}{ LO } & \multicolumn{2}{|c|}{ Quality of student work. Student... } \\
\hline & & & $\mathrm{S}$ & $\begin{array}{l}\text { knows his/her role in the performance and can explain why that } \\
\text { role is essential to the simulation }\end{array}$ \\
\hline & & & G & $\begin{array}{l}\text { knows his/her role and knows the parameters, but does not } \\
\text { explain the connection between them. }\end{array}$ \\
\hline & & & NI & identifies parameters but does not explain them. \\
\hline & & & $\mathrm{U}$ & does not identify parameters. \\
\hline \multirow[t]{4}{*}{$\begin{array}{l}\text { Outcomes of simulation are clearly } \\
\text { diagrammed }\end{array}$} & 1 & I, IV & $\mathrm{S}$ & $\begin{array}{l}\text { produces a clear, easy to read diagram that continues through } \\
\text { enough rounds to predict the possible outcomes accurately } \\
\text { (e.g., Fig. 2). }\end{array}$ \\
\hline & & & G & $\begin{array}{l}\text { produces an accurate diagram that continues through enough } \\
\text { rounds to predict the possible outcomes accurately, but } \\
\text { diagram lacks clarity. }\end{array}$ \\
\hline & & & NI & $\begin{array}{l}\text { produces an inaccurate and confusing diagram and/or does not } \\
\text { continue through enough rounds to predict the possible } \\
\text { outcomes. }\end{array}$ \\
\hline & & & $\mathrm{U}$ & $\begin{array}{l}\text { diagrams only one round and thus does not include predictions } \\
\text { or parameters reveal serious misconceptions. }\end{array}$ \\
\hline \multirow[t]{4}{*}{$\begin{array}{l}\text { Mutation, genetic drift, or migration cause } \\
\text { heritable change during the simulation }\end{array}$} & 5 & II, IV & $\mathrm{S}$ & $\begin{array}{l}\text { clearly and accurately portrays how mutation, drift, or } \\
\text { migration leads to a change in the proportion of a } \\
\text { characteristic through generations; may include natural } \\
\text { selection working in concert with another mechanism of } \\
\text { evolution. }\end{array}$ \\
\hline & & & G & $\begin{array}{l}\text { hints at how mutation, drift, or migration leads to a change in } \\
\text { the proportion of a characteristic through generations, but } \\
\text { lacks clarity. }\end{array}$ \\
\hline & & & NI & inaccurately portrays mutation, drift, or migration. \\
\hline & & & $\mathrm{U}$ & $\begin{array}{l}\text { does not invoke a mechanism of evolution other than natural } \\
\text { selection. }\end{array}$ \\
\hline \multirow[t]{4}{*}{$\begin{array}{l}\text { Clear distinction between sorting, creative, } \\
\text { and random processes invoked by } \\
\text { different simulations }\end{array}$} & $4,4 a, 4 c$ & III, IV & $\mathrm{S}$ & $\begin{array}{l}\text { recognizes that natural selection is a sorting process, that } \\
\text { mutation is a creative process, that genetic drift is random, } \\
\text { and that migration may a sorting process, that it may be } \\
\text { creative (by adding alleles to a population), or that it may } \\
\text { be random. }\end{array}$ \\
\hline & & & G & $\begin{array}{l}\text { recognizes that natural selection is a sorting process, that mutation } \\
\text { is a creative process, that genetic drift is random, but does not } \\
\text { address the fact that migration can be a sorting, creative, or } \\
\text { random process. }\end{array}$ \\
\hline & & & NI & $\begin{array}{l}\text { distinguishes between sorting and creative processes, but cannot } \\
\text { recognize random processes. }\end{array}$ \\
\hline & & & $\mathrm{U}$ & does not distinguish between sorting and creative processes. \\
\hline \multirow{4}{*}{$\begin{array}{l}\text { Clearly defined rounds that include } \\
\text { reproduction; explains why reproduction } \\
\text { is necessary to effect change via this } \\
\text { mechanism }\end{array}$} & $1,4 \mathrm{c}$ & I, II, IV & $\mathrm{S}$ & $\begin{array}{l}\text { recognizes that reproduction involves heritability and that heritability } \\
\text { is an essential component of evolution. }\end{array}$ \\
\hline & & & G & $\begin{array}{l}\text { recognizes that reproduction involves heritability, but does not } \\
\text { recognize that heritability is required for a change in proportions } \\
\text { to persist into a new generation. }\end{array}$ \\
\hline & & & NI & $\begin{array}{l}\text { includes reproduction, but does not explain the role of reproduction } \\
\text { in this simulation }\end{array}$ \\
\hline & & & $\mathrm{U}$ & does not include reproduction in simulation. \\
\hline \multirow[t]{4}{*}{$\begin{array}{l}\text { Analyzes the limitations and simplifications } \\
\text { of the simulation }\end{array}$} & All & II, IV & $\mathrm{S}$ & $\begin{array}{l}\text { recognizes that the performance is an analogy, accurately analyzes } \\
\text { the limitations of the analogy. }\end{array}$ \\
\hline & & & $\mathrm{G}$ & $\begin{array}{l}\text { recognizes that the performance is an analogy, but struggles to } \\
\text { identify and/or analyze the limitations of the analogy. }\end{array}$ \\
\hline & & & NI & $\begin{array}{l}\text { acknowledges that analogies have limitations, but does } \\
\text { not identify any. }\end{array}$ \\
\hline & & & $\mathrm{U}$ & ignores the limitations of the analogy. \\
\hline
\end{tabular}


Table 5 (continued)

\begin{tabular}{|c|c|c|c|c|}
\hline Criterion & $\mathrm{C}$ & LO & \multicolumn{2}{|c|}{ Quality of student work. Student... } \\
\hline \multirow[t]{4}{*}{$\begin{array}{l}\text { Generates a series of questions to analyze } \\
\text { the simulation }\end{array}$} & All & IV & $\mathrm{S}$ & $\begin{array}{l}\text { presents a series of thoughtful questions that work up } \\
\text { Bloom's taxonomy from knowing to evaluating and } \\
\text { synthesizing broader evolutionary questions } \\
\text { (Bloom et al. 1956). }\end{array}$ \\
\hline & & & G & $\begin{array}{l}\text { presents a series of thoughtful questions that work up } \\
\text { Bloom's taxonomy, but does not extend beyond the } \\
\text { scope of the performance to broader evolutionary } \\
\text { questions. }\end{array}$ \\
\hline & & & NI & $\begin{array}{l}\text { presents a series of thoughtful questions that apply and } \\
\text { analyze basic knowledge, but does not evaluate or } \\
\text { synthesize that knowledge. }\end{array}$ \\
\hline & & & $\mathrm{U}$ & $\begin{array}{l}\text { presents one or two questions that target only low level } \\
\text { thinking }\end{array}$ \\
\hline \multirow{4}{*}{$\begin{array}{l}\text { Compare the simulation to real examples } \\
\text { invoking the same mechanism(s) of } \\
\text { evolution }\end{array}$} & - & II, IV & $\mathrm{S}$ & $\begin{array}{l}\text { finds several examples and compares each to the simulation } \\
\text { and to each other, noting similarities and differences }\end{array}$ \\
\hline & & & G & $\begin{array}{l}\text { finds several examples and compares each to the simulation, } \\
\text { but not to each other. }\end{array}$ \\
\hline & & & NI & $\begin{array}{l}\text { identifies just one example and does not probe for similarities } \\
\text { and differences }\end{array}$ \\
\hline & & & $\mathrm{U}$ & does not choose examples that invoke the same mechanism(s). \\
\hline
\end{tabular}

Learning objectives keyed to Table 2; other abbreviations follow Table 3

al. 2000). To encourage metacognitive reflection, I ask students to juxtapose their performances onto a flow chart depicting the scientific method (Understanding Science 2010). They include the notes they took, the hypotheses that they formed and revised, and the discussions they had, articulating how each piece contributed to their learning. Students can choose the best way to represent this reflection: verbal learners, for example, might use outlines, and visual learners could present a concept map.

\section{Case Studies}

A number of brief descriptions of natural selection are readily available on the Internet through the Understanding Evolution (2010) and the National Evolutionary Synthesis Center (NESCent 2010) websites. Students work through the case studies by answering slightly modified versions of the questions in Table 4:

- How does this case study illustrate heritable variation in a population?

- How do you know more offspring are born than can survive?

- Illustrate how natural selection affects this population, indicating how and why individuals are sorted. Describe how the frequency of different traits changes from generation to generation.

- What kinds of environmental change would alter the selective pressures?
Another kind of case study asks students to correct misconceptions. Some diagrams, for example, depict common intuitive yet incorrect interpretations of natural selection (e.g., Fig. 2 in Gregory 2009). The instructor can distribute copies of confusing or inaccurate figures and have students generate new figures that are clear and accurate.

\section{Designing a New Simulation}

A powerful way to assess how well students understand these concepts is to ask them to choreograph their own performances (Aubusson and Fogwill 2006; Nikitina 2003) to model other mechanisms that change the frequency of traits in a population. By designing their own performances, students identify where they are confused and work collaboratively to improve their understanding (Aubusson and Fogwill 2006). After introducing mutation, genetic drift, and migration, students work in small groups to choreograph how each of these mechanisms can lead to heritable change. The students map their simulations (as in Fig. 2) and generate a series of questions that analyze the performance. Then, students perform each others' simulations. Finally, students compare their simulations to real-life examples of evolution occurring by the mechanism they invoked. This act of choreography summarizes the fundamental concepts about natural selection that were introduced in the previous activities (Table 1), reviews the learning goals and outcomes (Table 2), and applies their newly constructed knowledge to solve a new problem. Table 5 presents a rubric for evaluating the new 
performances and explicates how the performance aligns with the concepts, learning goals, and outcomes.

\section{Conclusion}

By the time students reach college, their understanding of evolution is limited and full of misconceptions (Jakobi 2010). Learning evolutionary fundamentals through performancebased activities offers a new context for introducing evolution that breaks traditional barriers. Moving through the classroom excites interest. Students experience a sorting process by participating in one, an approach that I find to be particular efficient at introducing fundamental concepts.

The hook offered by performance is an introduction-a game - that needs to be supplemented with thoughtful discussion. Students learn from the performances by treating them like mini-experiments, formulating hypotheses, collecting data and, especially, analyzing their results (Harrison and Treagust 2006). Thus, the questions at the end of the performances are absolutely critical for gaining the sophisticated understanding described in the rubrics (Tables 3-5) and for thinking critically about the analogies that the performances represent (Harrison and Treagust 2006).

Anecdotally, these performances have been extremely successful. Students have fun during the simulations, and they immediately begin grappling with the concepts that I am trying to teach, nodding and talking as they learn. When I see students again in other classes, they remember the poses they adopted and use those memories to think about different evolutionary processes. I have planned formal evaluation of these activities to (1) document what students learn, (2) quantify the degree of conceptual change, (3) compare student enthusiasm for this approach with others, (4) assess long-term retention of the knowledge acquired, and (5) determine how student understanding before and after the performances varies among biology students, students in other areas of science, and non-science students.

Acknowledgments I thank Kory Perigo and the students of Discovery Core I in 2007-2009 for participating in these exercises, Kanta Kochhar-Lindgren for introducing me to performance-based learning, and to David Goldstein, Karen Gourd, and Marc Servetnick for their editorial suggestions.

\section{References}

Anderson DL, Fisher KM, Norman GJ. Development and evaluation of the conceptual inventory of natural selection. J Res Sci Teach. 2002;39(10):952-78. doi:10.1002/tea.10053.

Aubusson PJ, Fogwill S. Role play as analogical modelling in science. In: Metaphor and analogy in science education. Dordecht, The Netherlands: Springer; 2006. p. 93-104.
Bloom BS, Krathwohl DR, Masia BB. Taxonomy of educational objectives: the classification of educational goals. New York: D. McKay; 1956.

Boal A. Games for actors and non-actors. 2nd ed. New York: Routledge; 2002.

Bransford JD, Brown AL, Cocking RR. How people learn: brain, mind, experience, and school. Expanded ed. Washington, D.C.: National Academy Press; 2000.

Cook SW, Mitchell Z, Goldin-Meadow S. Gesture makes learning last. Cognition. 2008;106(2):1047-58. doi:10.1016/j.cogni tion.2007.04.010.

Crouch CH, Fagen AP, Callan JP, Mazur E. Classroom demonstrations: learning tools or entertainment? Am J Phys. 2004;72 (6):835-8.

Felder RM, Brent R. Understanding student differences. J Eng Educ. 2005;94(1):57-72.

Gregory TR. Understanding natural selection: essential concepts and common misconceptions. Evol Edu Outreach. 2009;2:156-75. doi:10.1007/s12052-009-0128-1.

Handelsman J, Miller S, Pfund C. Scientific teaching. New York: W. H. Freeman and Company; 2007.

Harrison AG, Treagust DF. Teaching and learning with analogies: friend or foe? In: Metaphor and analogy in science education. Dordecht, The Netherlands: Springer; 2006. p. 11-24.

Harrison-Pepper S. Dramas of persuasion: performance studies and interdisciplinary education. Theatre Top. 1999;9(2):141-56.

Jakobi SR. "Little monkeys on the grass..." How people for and against evolution fail to understand the theory of evolution. Evol Edu Outreach. 2010;3:416-9. doi:10.1007/s12052-0100214-4.

Kreiser B, Hairston R. Dance of the chromosomes: a kinetic learning approach to mitosis and meiosis. Bioscene. 2007;33(1):6-10.

Mead LS, Scott EC. Problem concepts in evolution Part I: purpose and design. Evol Edu Outreach. 2010a;3:78-81. doi:10.1007/s12052010-0210-8.

Mead LS, Scott EC. Problem concepts in evolution Part II: cause and chance. Evol Edu Outreach. 2010b;3:261-4. doi:10.1007/ s12052-010-0231-3.

Miller KR. Finding Darwin's God: a scientist's search for common ground between God and evolution. New York: HarperCollins; 2002.

NESCent. Examples of evolution: selective pressures and adaptation 2010.http://www.nescent.org/eog/generalexamples.php\#Natural. Accessed July 22, 2010.

Nikitina S. Movement class as an integrative experience: academic, cognitive, and social effects. J Aesthet Educ. 2003;37(1):54-63.

Reid J. The learning style preferences of ESL students. TESOL Q. 1987;21(1):87-111.

Scott EC. Listening to teachers. Evol Edu Outreach. 2010;3(2):241-4. doi:10.1007/s12052-010-0218-0.

Sinatra GM, Brem SK, Evans EM. Changing minds? Implications of conceptual change for teaching and learning about biological evolution. Evol Edu Outreach. 2008;1:189-95. doi:10.1007/ s12052-008-0037-8.

Understanding Evolution. Examples of evolution; 2010.http://evolution. berkeley.edu/evolibrary/search/topicbrowse2.php?topic_id=52. Accessed July 22, 2010.

Understanding Science. The real process of science; 2010.http:// undsci.berkeley.edu/article/0_0_0/howscienceworks_02. Accessed July 22, 2010.

Weiss RA (Director). Protein synthesis: an epic on the cellular level. [online video] http://www.youtube.com/watch? $\mathrm{v}=\mathrm{u} 9 \mathrm{dhO} 0 \mathrm{iCLww}$; 1971. Accessed July 22, 2010.

Wilson DS. Evolution for everyone: how to increase acceptance of, interest in, and knowledge about evolution. PLoS Biol. 2005;3 (12):e364. doi:10.1371/journal.pbio.0030364. 